\title{
UMA ESCUTA ÉTICA DE PSICOLOGIA AMBIENTAL
}

\author{
José Célio Freire \\ Emanuel Meireles Vieira \\ Universidade Federal do Ceará
}

\begin{abstract}
RESUMO: O artigo propõe uma nova abordagem da dimensão ética da Psicologia Ambiental e da educação ambiental, a partir da ética da alteridade radical de Emmanuel Lévinas. Inicia com uma síntese das várias perspectivas da Psicologia Ambiental e da Ética Ambiental para, em seguida, tratar de conceitos centrais da Psicologia Ambiental apropriação do espaço, identidade de lugar e pertencimento - à luz de uma ética radicalizada.
\end{abstract}

PALAVRAS-CHAVE: ética; psicologia ambiental; alteridade.

\section{ETHICAL LISTENING OF ENVIRONMENTAL PSYCHOLOGY}

ABSTRACT: The article proposes a new approach of the ethical dimension of the Environmental Psychology and the environmental education, from Emmanuel Levinas's ethics of radical alterity. It begins with a synthesis of the many perspectives of environmental psychology and the environmental ethics in order to, after that, approach central concepts of the environmental psychology - space appropriation, place identity, and belonging - based on a radicalized ethics.

KEYWORDS: ethics; environmental psychology; alterity.

\section{O âmbito da Psicologia Ambiental}

A definição de Moser (1998), de que "a psicologia ambiental estuda a pessoa em seu contexto, tendo como tema central as interrelações - e não somente as relações entre a pessoa e o meio ambiente físico e social" (p.121), nos lança diversas questões a respeito da maneira como estas "inter-relações" são abordadas. Por isso, na história desta área da Psicologia, podemos perceber diversas vertentes.

No período que Aragonés e Amérigo (1998) denominam pré-história da Psicologia Ambiental - o primeiro nascimento a que se refere Valera (1996), ligado a um modelo mais positivista de ciência - pode-se compreender variações que vão do introspeccionismo de Wundt à Psicologia da Gestalt, englobando aspectos mais atomísticos e holísticos, e aí se destacando os trabalhos de Brunswik e Lewin. Aragonés e Amérigo (1998) dividem o segundo nascimento (Valera, 1996), em que há uma redefinição dos métodos de trabalho da Psicologia Ambiental numa direção mais social - satisfação residencial e qualidade de vida - em dois períodos: o de institucionalização, em que este campo do conhecimento ganha o caráter de disciplina (década de 1970), mesmo que ainda sem estrutura, e o período de consolidação e desenvolvimento, de 1980 até os dias atuais. Neste, há uma ampliação dos espaços de fomentação e difusão desta disciplina em revistas especializadas, instituições e universidades.

A multiplicidade de perspectivas também repercute nos diálogos interdisciplinares que a Psicologia Ambiental estabelece, sendo os principais destaques a arquitetura, a geografia, a ecologia, as ciências sociais e as diversas áreas da Psicologia, como a social, a comunitária e, até mesmo, o comportamentalismo. Desse modo, podemos definir a atuação em Psicologia Ambiental como interdisciplinar e transdisciplinar, inclusive devido ao fato de ser recente a "criação" desta área como vinculada à Psicologia, o que dificulta a especificação do que lhe seria um campo próprio e exclusivo de estudos.

Valera (1996), por exemplo, define a Psicologia Ambiental como uma “(...) disciplina que tem por objeto o estudo e a compreensão dos processos psicossociais derivados das relações, interações e transações entre as pessoas, grupos sociais ou comunidades e seus entornos sociofísicos" (p.2). Percebemos que amplia a definição de Moser (1998), no sentido de uma compreensão de processos sociais, possibilitando uma maior aproximação entre Psicologia Ambiental e Psicologia Social ou, até mesmo, Psicologia Comunitária, o que para Moser (1998) não é possível, pois a pesquisa-ação não faria parte dos meios de atuação da Psicologia Ambiental.

De acordo com Moser (1998), temos duas abordagens extremas na Psicologia ambiental: uma experimental e outra que realiza uma análise sistemática da inter-relação pessoaambiente, sem privilégio de uma das partes isoladamente, pois se compreende que ambas fazem parte de um todo, um sistema. Além desta primeira subdivisão, Valera (1996) define, a partir das "visões de mundo" em psicologia, de Altman e Rogoff (1987, citados em Aragonés \& Amérigo, 1998), quatro perspectivas no desenvolvimento da Psicologia Ambiental: a individualista, a interacionista, a organísmica e a transacionalista.

À abordagem individualista corresponde a compreensão de que o indivíduo é o foco, cabendo à Psicologia seu estudo em termos de processos mentais ou psicológicos. $\mathrm{Na}$ abordagem interacionista, há interação entre a pessoa e o 
entorno, mas são tratados de maneira separada, sendo a Psicologia responsável pela predição e controle dos processos psicológicos. Já a perspectiva organísmica afirma a interação de elementos da pessoa e do entorno, que fazem parte de um todo que é maior que a soma de suas partes, cabendo à Psicologia o estudo de sistemas dinâmicos e holísticos em que se dão complexas relações e influências. A última abordagem, a transacionalista (ou transacional), compreende pessoa e ambiente como aspectos de uma unidade holística de análise e não como partes ou elementos separados. Teremos em mente esta abordagem ao efetuarmos uma escuta ética da Psicologia Ambiental, a partir de uma visada levinasiana (Lévinas, 1988, 2000).

\section{Perspectivas em Ética Ambiental}

A ética ambiental não comparece com ênfase nos estudos desenvolvidos na área, embora os temas de investigação e discussão sejam numerosos (Aragonés \& Amérigo, 1998; Stokols, 1995; Wiesenfeld, 2001). Contextos, atores, problemas ambientais, processos psicológicos envolvidos e tipos de intervenção diversos são objeto de pesquisa neste campo, mas a dimensão ética da relação humanoambiental não adquire status de questionamento fundamental. Wiesenfeld (2001) trata de uma questão eminentemente ética quando exemplifica uma intervenção com consequiências para a população envolvida, mas não a assume por esse ângulo. Já Stokols (1995), ao defender abordagens mais compreensivas para o planejamento comunitário, propõe considerar diferenças éticas na resposta das pessoas, mas ainda deixa de lado a responsabilidade ética anterior, se assim podemos dizer, do investigador em relação aos sujeitos envolvidos em seus estudos e, indo mais além, do estudioso frente ao seu objeto - o ambiente - em sua diferença e alteridade.

Freire (in press) faz um ligeiro apanhado quanto às várias "éticas ambientais", do estoicismo e epicurismo à ética da responsabilidade de Hans Jonas, passando por Schopenhauer e Hume. A partir de Pelizzoli (2002), confronta os modelos éticos neoliberal (utilitarista, conservador e reformista), ecossocialista (anticapitalista, crítico da globalização, da tecnificação e da democracia formal), holístico (restaurador da harmonia com o cosmos), biocêntrico (de união, integração e celebração com a natureza), cristão (criacionista e sacro), budista (da dignidade e interligação de todos os seres), da responsabilidade (da contenção e da moderação da intervenção tecnológica), da alteridade radical (da natureza e do ambiente como outrem), da teoria crítica (próximo do modelo ecossocialista, crítico da razão instrumental e técnica) e, por último, o hermenêutico (de observação da natureza e da vida).

A radicalização do pensamento ético, efetuada por Lévinas (1988), aproximada da discussão ecológica por Freire (no prelo), implica na não-indiferença para com a diferença do outro da natureza ou do ambiente. Em outras palavras, significa respeitar a natureza sem subsumi-la no humano, o que significaria aniquilar a sua diferença irredutível. Em última instância, trata-se de uma responsabilidade pelo outro da natureza ou pelo outro como ambiente exterior a mim e, ao mesmo tempo, da responsabilidade pelos outros que habitam o mundo, ou que virão a habitá-lo (Freire, in press). É a partir desta visada ética que empreenderemos, neste estudo, uma crítica e uma proposição teórica para a Psicologia Ambiental. Faremos isso em relação ao modelo transacionalista, exposto na primeira seção deste artigo, e tomando a noção de apropriação do espaço e conceitos que lhe são correlatos, como identidade de lugar e pertencimento.

\section{Conceitos-chave em Psicologia Ambiental}

Uma categoria fundamental para a Psicologia Ambiental na perspectiva transacionalista é a apropriação do espaço, advinda, de acordo com Pol (1996), das filosofias de Marx e Heidegger. Para Lauwe

(...) apropriar-se de um lugar não é só fazer dele uma utilização reconhecida senão estabelecer uma relação com ele, integrá-lo nas próprias vivências, enraizar-se e deixar a própria marca, organizá-lo e tornar-se ator de sua transformação. (citado em Pol, 1996, p.51)

Como se pode perceber, está implícita aqui a noção de que as pessoas deixam marcas suas e se apossam do espaço, tornando-o um lugar (Bomfim, 2003), formando com ele uma unidade, em que um reflete um pouco do outro. A apropriação, de acordo com Pol (1996), vem se contrapor à noção, também marxiana, de alienação. A apropriação do espaço, por conseguinte, seria a identificação do indivíduo relativa ao espaço com o qual está em inter-relação.

Segundo Pol (1996), haveria duas componentes básicas no processo de apropriação do espaço: a ação-transformação e a identificação. A primeira diz respeito não à demarcação do território, mas a uma ocupação territorial mais complexa, onde há ação concreta das pessoas sobre o entorno, de acordo com a vontade e a intencionalidade do indivíduo. Já no processo de identificação (simbólico), o espaço se torna lugar pela identificação do sujeito ou grupo social com o entorno (Pol, 1996), sendo um processo mais elaborado que o de ação-transformação, embora ambos atuem de maneira cíclica e processual.

Num primeiro momento, cria-se a identidade a partir de uma interação. Num momento posterior, esta identidade de lugar tende a ser preservada, principalmente em pessoas mais velhas. A apropriação pode se dar tanto em espaços públicos quanto em privados, sendo que no primeiro caso este processo se daria mais predominantemente por identificação, enquanto que no segundo caso a componente da ação-transformação seria, a princípio, predominante (Pol, 1996).

Para Valera e Pol (1999) há uma intrínseca relação 
entre o modo como as pessoas simbolizam o espaço e sua relação para consigo (identidade pessoal) e com o mundo (identidade social). Aliás, para o autor, estas duas componentes da identidade estão apoiadas na identidade de lugar, o que confere uma importância crucial a esta última. De acordo com esta perspectiva, quanto mais identificação houver entre o indivíduo e seu entorno, maior a possibilidade de um comportamento de preservação do ambiente. Isto pode ser explicado se tivermos em mente que, já que há uma identificação entre indivíduo e ambiente, caso o indivíduo aja de maneira destrutiva em relação ao ambiente, estaria destruindo a si próprio.

Para uma melhor compreensão deste processo, fazse necessário que iniciemos uma discussão em torno da noção de identidade. De acordo com Jacques (2003), a identi-dade oscila entre o particular e o coletivo,uma vez que, ao mesmo tempo em que diz respeito a uma singularidade do sujeito, traz à tona a compreensão de que este mesmo sujeito está imerso numa série de relações sociais. Já Ciam-pa (1995) traz-nos uma definição de identidade como metamorfose, que, ao invés de refletir uma essência do indivíduo, diria respeito a um processo de ocultação e revelação. De acordo com este autor, o processo de construção da identidade envolve tanto diferença quanto desigualdade, portanto a identidade traz consigo uma possibilidade de alterização de si, rompimento (ou não) com uma identidade pressuposta.

Retomando o tema da identidade de lugar, podemos concluir que ela se refere ao que no espaço remete ao sujeito. Deste modo, conforme Valera e Pol (1999), o simbo-lismo do espaço e a identidade de lugar estariam vinculados à identidade social, pois o lugar seria uma referência na constituição das identidades daqueles que dele fazem parte. Poderíamos, inclusive, renomear a identidade de lugar como identidade social de lugar, o que nos leva à afirmação de que o lugar faz parte daquilo que somos e do que nos faz ser reconhecidos.

Segundo Twigger e Uzzel (1996), o lugar tem um papel de bastante relevância na constituição da identidade e pode ser considerado como uma categoria social sujeita às mesmas regras da identificação social, no âmbito da teoria da identidade social (p.206). Segundo esses autores, o processo da identidade de lugar é condicionado por quatro princípios, a saber: distinção, continuidade, autoestima e auto-eficácia.

A distinção diz respeito ao fato de que as pessoas "têm um tipo específico de relacionamento com seu ambiente nativo, que é claramente distinto de qualquer tipo de relacionamento" (Twigger \& Uzzel, 1996, p.207). Já a continuidade se refere à relação entre a manutenção do espaço e a do próprio indivíduo. Deste modo, preservar um ambiente com o qual se identifica é manter a própria identidade. $\mathrm{O}$ princípio da auto-estima se refere à influência do ambiente em relação a um sentimento de estima por si mesmo. Por último, a auto-eficácia se refere à capacidade de o ambiente facilitar, ou pelo menos não atrapalhar, as atividades do dia-a-dia de uma pessoa; quanto mais "facilitador" for o ambiente, mais se mantém este sentimento de auto-eficácia.

Para Bomfim (2003), o processo participativo dos cidadãos, no que diz respeito ao planejamento, permite a apropriação por parte dos mesmos e, desta forma, fortalece a identidade de lugar destes. $\mathrm{O}$ fortalecimento da identidade de lugar favoreceria um apego do indivíduo em relação ao entorno, o que estimularia uma ética do cuidado (Bomfim, 2003) para com o ambiente, em que este não se limita a sua dimensão física, senão que carrega consigo valores e formas de organização da sociedade (como a segregação social a partir do espaço, por exemplo).

\section{Alteridade e Psicologia Ambiental}

Partir da ética da alteridade radical de Emmanuel Lévinas implica na consideração do ambiente como um Outro, ou seja, absolutamente diferente de mim e, por isso mesmo, não-totalizável. Nossa pretensão, todavia, não é a criação de um modelo para uma psicologia ambiental ética, mas sim de um rastro de leitura diferante. ${ }^{1}$ Além disto, como nos adverte Pelizolli (2002), Lévinas não tinha na natureza um tema específico de sua filosofia, que pode ser identificada inclusive como antropocêntrica.

Tomando a apropriação do espaço a partir de uma crítica ética, entendemos que essa resignificação do espaço pelos sujeitos implica em que "Sentir um lugar, uma coletividade, um entorno como próprio, facilita o envolvimento e a responsabilidade de sua gestão e de desenvolvimento de comportamentos respeitosos e sustentáveis" (Pol, 1999, p.59). Todavia, apropriar é tornar próprio, ou seja, absorver o Outro no Mesmo. De uma perspectiva hermenêutica, em última instância ética, veremos que tal postura - seja ela epistemológica ou de intervenção prática - se opõe à atitude de respeito ao Outro (e, aqui, a Natureza ou o ambiente) em sua diferença, reduzindo-o ao Próprio, ao Mesmo, ao que já se conhece e sob o que se exerce um domínio. Ora, o Outro é o diferente, mas em relação a que(m) não se pode ser indiferente. Logo, é incongruente que se tente apropriar-se dele. Não se pode ser indiferente ao entorno, de onde se mora ao universo de que se é minúscula parte. Contudo, a responsabilidade que nos incumbe a todos, a partir da exigência que o ambiente nos faz, não nos torna o mesmo que ele ou donos dele. Todavia, isso "não nos redime da responsabilidade social para com o ambiente" (Freire, in press).

Do ponto de vista da ética da alteridade, portanto, a Psicologia Ambiental traria a marca da violência a partir da noção de apropriação, uma vez que não posso possuir o Outro. Se compreendermos o ambiente como exterioridade, 
o absolutamente Outro, perceberemos que, mesmo que exista um movimento de apropriação em relação a este - perspectiva imanente, privilegiando uma interioridade-não há como negar que os ambientes também se apro-priam de nós. E aí reside uma violência sobre a Psicologia Ambiental, já que o espaço apropriante é visto como algo prejudicial que dificulta a transformação (Pol, 1996). Contudo, questionamos: quem nunca se referiu a seu lugar de origem como aquele a que o sujeito pertence e não o contrário?

Numa mesma direção nos chega a questão da territorialidade. Há os que apregoam a "desterritorialização", que seria um dos atributos da pós-modernidade, no sentido em que substitui lugares identitários por não-lugares (Augé, 1994) onde as diferenças, apesar de defendidas, se liquefazem na experiência cotidiana. Outros defendem o surgimento de novos espaços, na modernidade tardia, através de resignificações e da consolidação de novas formas de territorialização (Haesbaert, 2002).

Etimologicamente, "pertencer a" é "ser propriedade de" ou "fazer parte de", que podemos referir à relação do sujeito com o lugar. O sentimento de estranhamento seria o seu oposto. De uma perspectiva radicalizada, os lugares não me pertencem, ou seja, minha casa não é minha casa, já que é usurpação do lugar do outro. Visto de uma outra maneira: pertencemos aos lugares e não eles a nós. Assim, pertencemos a todos os lugares que já habitamos, sendo ligados a eles pelos sentimentos que neles experimentamos. Não obstante, esse pertencimento é estranho, pois o mundo é inóspito.

Portanto, de uma posição ética radicalizada frente à natureza, soa muito estranho falarmos de apropriação e de pertença, no sentido que tais expressões têm para nós. "Apropriar-se do ambiente ou pertencer à natureza, em última instância invalidam a condição de estranheidade do mundo, ou seja, a garantia de sua diferença, a qual não devemos ser indiferentes" (Freire, in press).

Giddens (1991), por sua vez, traz-nos a noção de desencaixe entre tempo e espaço, dado que, em situações cotidianas de uma modernidade radicalizada, não é mais necessário estar num determinado lugar para ter incidência sobre ele. Este desencaixe é, segundo Haesbaert (2002), uma outra forma de conceber a territorialização, e não seu fim, pois o território faz parte da fundamentação ontológica do ser humano.

Se tomarmos a proposta biocêntrica como exemplo de uma perspectiva transacionalista, e entendendo que ela busca avançar em relação às perspectivas teocêntrica e antropocêntrica (Vecchia, 2001), centrando sua força na afetividade e na consciência, perceberemos, não obstante, que cede ao apelo romântico. A ética, nesse caso, é uma atitude interna de integração profunda com a natureza, movida pela energia do amor na vivência do divino (Vecchia, 2001, p.310). Essa proposta, apesar de mostrar uma abertura para o outro - e a Natureza, em especial -, não se faz respeitando as diferenças, mas diluindo-as ou apagando-as em apelos de "união", "celebração" e "integração". Tal proposta se complementaria com a "compaixão pela Terra" de Leonardo Boff. Dessa maneira, "Ético é tudo aquilo que 'ajuda a tornar melhor o ambiente [casa, localidade, planeta] para que seja uma moradia saudável: materialmente sustentável, psicologicamente integrada e espiritualmente fecunda"" (Boff citado em Vecchia, 2001, p.24). A escuta da natureza implica, então, num processo de identificação: "o homem precisa sentir-se natureza" (Vecchia, 2001, p.43). Trata-se de uma visão oposta ao reconhecimento da alteridade radical, das diferenças irreconciliáveis e da separação Mim-Outro. Essa "naturalização" da diferença do homem para com o Outro da Natureza implica em o homem perder sua humanidade, aquilo que o faz distinto desta própria natureza.

Mas que possibilidades apresenta a Psicologia Ambiental, para o acolhimento da estranheza do Outro? Afinal de contas, a polissemia que atravessa este e outros discursos não nos apresenta nada que fuja à alergia do Outro? A afirmação de uma interioridade e de uma identidade que se mantém, conforme compreendemos, não elimina neste discurso a possibilidade de se pensar um lugar para a exterioridade absoluta, uma vez que, mesmo Lévinas (2000) não negava a possibilidade de se conceber o "Mesmo" e nem o via como oposição ao Outro. Deste modo, o que se questiona aqui é o privilégio dado à interioridade pela Psicologia Ambiental, em detrimento do que há de exterior na constituição da subjetividade.

Como proposta que apresenta uma potencialidade ética, podemos citar Bomfim (2003), que propõe uma metodologia que leva em conta a afetividade na relação pessoa-ambiente, denominada como "mapas afetivos". Trata-se de uma proposta alternativa aos mapas cognitivos, uma vez que a afetividade é compreendida como uma componente decisiva na ética ambiental enquanto cuidado para com o ambiente. Para Bomfim, "o significado na cidade está presente como sentimentos, na corporeidade. O corpo aparece não só como o acompanhante exterior das coisas, mas como o campo onde se localizam as afecções. Enquanto a afecção é a experiência, a corporeidade é o lugar da afecção" (2003, p.60). Deste modo, não apenas a pessoa deixa sua marca no ambiente, mas este também passa a marcá-la. Segundo Freire (2002), "A subjetividade, portanto, não é interioridade, mas um si constituído a partir de fora, de outrem, pura defecção de um eu que se perde a si mesmo" (p.85). Privilegiar a afecção na Psicologia Ambiental é tentar se aproximar de uma escuta do estrangeiro, como argumenta Pelizzoli (2002), no sentido de "aproximar a abordagem da natureza 
do conceito de Outro, interligar a ela o estatuto da alteridade, ou seja, ela é mais do que posso conhecer/ dominar; ela tem vida própria, e deve ser acolhida em sua dignidade" (p.110).

Esta concepção, no que pese guardar seus aspectos de imanência, nos indica um caminho para a educação ambiental, de um modo bem diverso do tradicional, pois neste o ambiente seria visto como objeto a ser conhecido, dissecado como objeto a partir do conhecimento. A educação ambiental, aqui, é compreendida em sua dimensão ética, a saber, a responsabilidade para com aquele que não sou eu, que está para além de mim. Deixemos falar Lévinas (1988): "Entendo responsabilidade por outrem (...) como responsabilidade por aquilo que não fui eu que fiz ou não me diz respeito" (p.87).

A natureza, portanto, não poderia ser vista como objeto que posso possuir, pois "é uma estrutura que, de modo algum, se assemelha à relação intencional que nos liga, no conhecimento, ao objecto, ainda que fosse um objecto humano" (Lévinas, 1988, p.89). Talvez, esta pudesse ser uma proposta ética para a Psicologia Ambiental, em seu aspecto pedagógico: uma experiência que, muito mais do que um conceito homogeneizante de dever, se dá como alterização de uma identidade e cuidado com o outro-de-si e com o outro-que-si - o ambiente a ser preservado em sua exterioridade.

A educação ambiental, portanto, não pode se transformar num simples manual de conduta, homogeneizador e totalizador de subjetividades, pois o ambiente (exterioridade) não diz respeito a um objeto. Aponta-se, então, como desafio, uma educação que preserve a singularidade, acolha (e não apenas tolere) a multiplicidade que constitui a humanidade do homem, que nada mais é do que o infinito em nós (Freire, 2002).

\section{Considerações Finais}

A Psicologia Ambiental, mesmo em suas correntes não-positivistas, apresenta uma certa alergia à alteridade do Outro, uma vez que, conforme pudemos observar, se mantém num plano de imanência, além do privilégio do idêntico, em detrimento do mutante. Aliás, a identidade de lugar parece-nos distinta do conceito de identidade tal como apresentado por Ciampa (1995), como metamorfose, pois esta seria uma identidade tensionada pelo movimento entre uma identidade pressuposta (estática) e uma posta (movimento).

Contudo, pensamos que mais do que a constatação da ausência do Outro levinasiano na Psicologia Ambiental, cabe-nos ressaltar mais desafios e questões advindas deste exercício de tensionamento de alguns textos desta importante e emergente área da Psicologia. Como tornar possíveis as idéias aqui propostas? Como escapar de uma totali- zação, quando se lida com um conhecimento aplicado? Como preservar esta "exterioridade" que tomamos com sendo o ambiente, sem cair num antropocentrismo, mesmo quando se fala de um biocentrismo? Como não cair numa saudade romântica de um passado que talvez nunca volte, se é que existiu (uma reunião harmoniosa entre homens e ambiente)? Que outras potencialidades éticas há na Psicologia Ambiental?

A estas questões não poderemos responder nos limites deste espaço; contudo, lança-se o desafio para investigações futuras que possam, tal como fizemos com relação às produções em Psicologia Ambiental, dialogar com este texto, em outros contextos, e produzir diferenças a partir das idéias e afetos que atravessaram este escrito.

\section{Notas}

1. Referimo-nos aqui ao termo différance, de Jacques Derrida, perspectiva usada para a elaboração deste trabalho, que diz respeito, por exemplo, ao encontro do leitor com o texto, utilizando-o como pretexto para a produção de outros textos.

\section{Referências}

Aragonés, J.I. \& Amérigo, M. (1988). Psicología ambiental: aspectos conceptuales y metodológicos. Em J.I. Aragonés \& M. Amérigo (Eds.), Psicología ambiental (pp.21-41). Madrid: Ediciones Pirâmide.

Augé, M. (1994). Não-lugares: introdução a uma antropologia da supermodernidade. Campinas: Papirus.

Bomfim, Z.A.C. (2003). Cidade e afetividade: estima e construção dos mapas afetivos de Barcelona e de São Paulo. Tese de Doutorado não-publicada, Programa de Pós-graduação em Psicologia Social, Pontifícia Universidade Católica de São Paulo. São Paulo, SP.

Ciampa, A.C. (1995). Identidade. Em S.T.M. Lane \& W. Codo (Eds.), Psicologia social: o homem em movimento (pp.58-75). São Paulo: Brasiliense.

Freire, J.C. (2002). O lugar do outro na modernidade tardia. São Paulo: Annablume, Fortaleza: Secult.

Freire, J.C. (in press) O outro da natureza: uma escuta ética do meio ambiente. Fortaleza. (manuscrito)

Giddens, A. (1991). As conseqüências da modernidade. São Paulo: Editora da Universidade Estadual Paulista.

Giddens, A. (1999). Modernidade e identidade. Rio de Janeiro: Jorge Zahar.

Haesbaert, R. (2002). Fim dos territórios ou novas territorialidades? Em L.P.M. Lopes \& L.C. Bastos (Eds), Identidades: recortes inter e multi-disciplinares (pp.29-51). Campinas, SP: Mercado de Letras.

Jacques, M.G.C. (2003). Identidade. Em M.G.C. Jacques; M.N. Strey; N.M.G. Bernardes; P. Guareschi; S.A. Carlos \& T.M.G. Fonseca (Eds.), Psicologia social contemporânea: livro texto (pp.159-167). Petrópolis, RJ: Vozes.

Lévinas, E. (1988). Ética e infinito. Lisboa: Edições 70.

Lévinas, E. (2000). Totalidade e infinito. Lisboa: Edições 70.

Moser, G. (1998). Psicologia ambiental. Estudos de Psicologia, 3(1), 121-130.

Pelizzoli, M.L. (2002). Correntes da ética ambiental. Petrópolis, RJ: Vozes. 
Pol, E. (1996). La apropriación del espacio. Em L. Iñiguez \& E. Pol (Eds.), Cognición, representación y apropiación del espacio (pp. 45-62). Barcelona: Publicacions Universitat de Barcelona.

Stokols, D. (1995). The paradox of environmental psychology. American Psychologist, 50(10), 821-837.

Twigger-Ross, C.L. \& Uzzel, D.L. (1996). Place and identity processes. Journal of Environmental Psychology, 16, 205-220.

Valera, S. (1996). Psicología ambiental: bases teóricas y epistemológicas. Em L. Iñiguez \& E. Pol (Eds.), Cognición, representación y apropiación del espacio (pp.1-14). Barcelona: Publicacions Universidad de Barcelona.

Valera, S. \& Pol, E. (1999). Symbolisme de l'espace public et identité sociale. Villes en Parallèle, 28-29, 13-33.

Vecchia, A.M.D. (2001). Ética: afetividade e cuidado pela vida. Pelotas: Educat.

Wiesenfeld, E. (2001). Tendências y perspectivas de desarrollo em Psicologia Ambiental. Em E. Tassara (Ed.), Panoramas interdisciplinares para uma psicologia ambiental do urbano (pp.27-49). São Paulo: EDUC/FAPESP.

José Célio Freire é professor pesquisador do Laboratório de Psicologia em Subjetividade e Sociedade (LAPSUS), vinculado ao Programa de Pós-Graduação em Psicologia da Universidade

Federal do Ceará, e ao Diretório de Grupos de Pesquisa do CNPq. Endereço: Rua Jornalista Olavo Araújo 12 - Aldeota, 60135-290, Fortaleza, CE. jcfreire@ufc.br

Emanuel Meireles Vieira é psicólogo, à época aluno do Curso de Psicologia da Universidade Federal do Ceará, membro do Núcleo de Psicologia Comunitária (NUCOM) e bolsista (PIBIC-CNPq) do Laboratório de Psicologia em Subjetividade e Sociedade (LAPSUS). emanuelmeireles@pop.com.br

\section{Uma escuta ética da psicologia ambiental}

José Célio Freire, Emanuel Meireles Vieira

Recebido: 13/12/2005

$1^{a}$ Revisão: $21 / 04 / 2006$

Aceite final: 05/07/2006

Apoio CNPq/PIBIC 